\title{
Murder of Şehzade Mustafa as an ordinary but very painful event in terms of the Ottoman history
}

\author{
Ali Ç. Turgut ${ }^{1}$ - Yașar B. Turgut ${ }^{2} \cdot$ Mehmet Turgut $^{3}$
}

Received: 4 August 2015 / Accepted: 10 August 2015 /Published online: 10 September 2015

(C) Springer-Verlag Berlin Heidelberg 2015

\section{Introduction}

Pediatric neurosurgeons are committed to not only treating physical neurological diseases of babies, children, and teens but also attending to the emotional health and social wellbeing of the kids (as well as their families) for success at home, at school, and in the community. There has been an increased number of research revealing that one of every four children is a stepchild at present, and it is anticipated that the stepfamily will be the predominant type of family in the future (http://www.dartmouth.edu/ eap/library/Wicked\% 2520 Stepmother\%2520Myth.doc). In the past, the stepmother's role was to replace a child's biological mother after her death, as it was in the Cinderella story, but it is most likely as a result of increased divorce rate in today's modern world. Apparently, a stepmother cannot be expected to show love and affection for a child in the extent that can be demonstrated by a biological mother. Therefore, the stepmother phenomenon is one of the most important factors

Mehmet Turgut

drmturgut@yahoo.com

Ali Ç. Turgut

alicaglar304.at@gmail.com

Yaşar B. Turgut

barroturgut@hotmail.com

Hacettepe University School of Medicine, 06100 Ankara, Turkey

2 Adnan Menderes University School of Medicine, 09100 Aydın, Turkey

3 Department of Neurosurgery, Adnan Menderes University School of Medicine, Cumhuriyet Mahallesi, Adnan Menderes Bulvarı, Haltur Apartmanı No: 6/7, 09020 Aydın, Turkey most likely to affect children and this may result in serious problems, as did in the following tragic story.

\section{Şehzade Mustafa, heir to Suleiman the Magnificent}

Şehzade Mustafa (1515-1553) was Suleiman the Magnificent's firstborn son by Mahidevran Sultan and therefore the

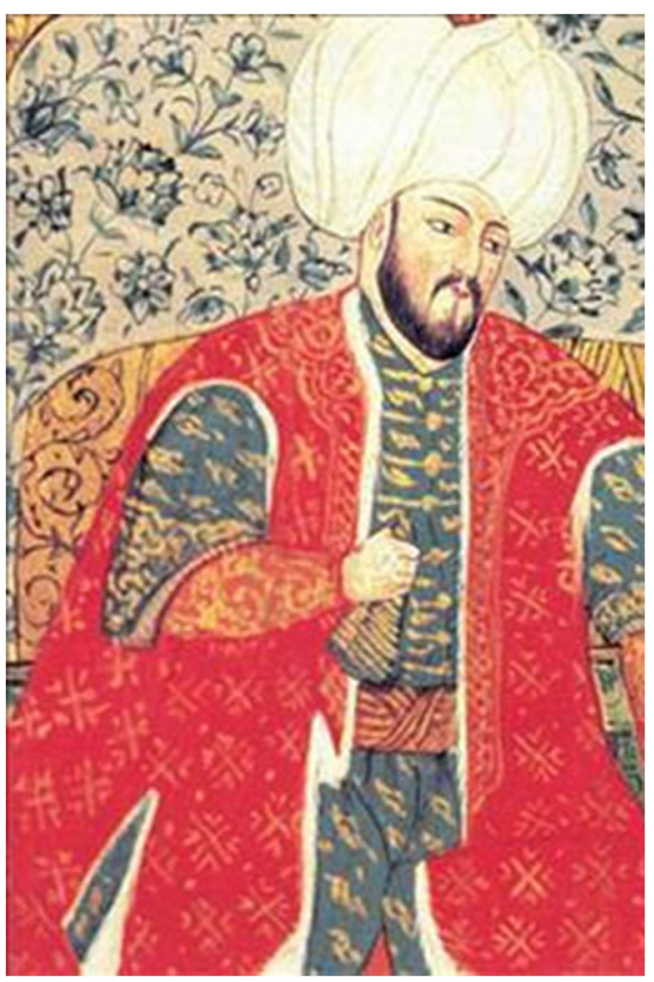

Fig. 1 An Ottoman miniature of Şehzade Mustafa (from https:// commons.wikimedia.org/wiki/File:Miniature_of_\%C5\%9Eehzade_ Mustafa.jpg) 


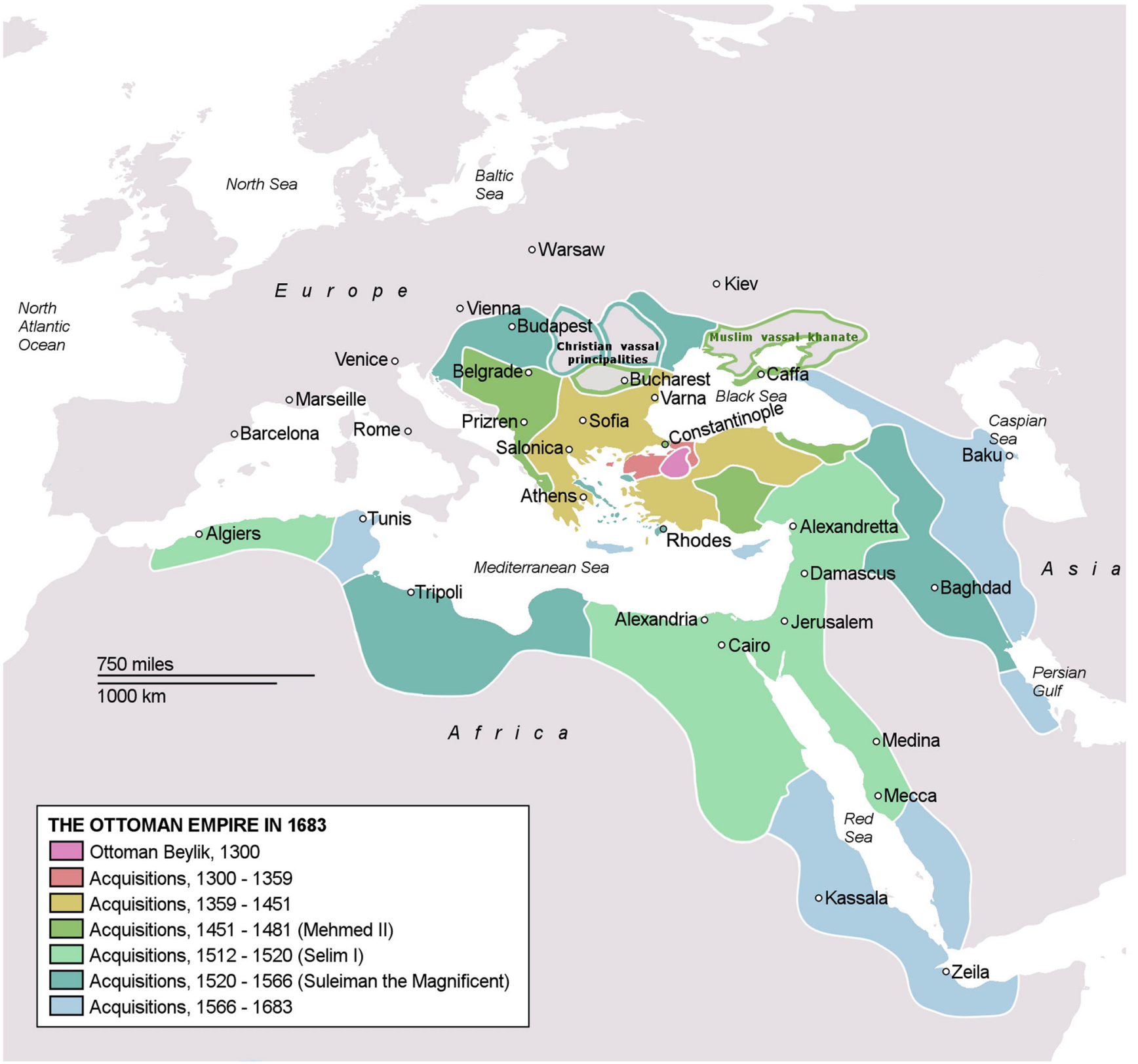

Fig. 2 The Ottoman Empire at its peak, in the late sixteenth century (from https://commons.wikimedia.org/wiki/File:OttomanEmpireIn1683.png)

apparent heir to the throne (Fig. 1) (https://commons. wikimedia.org/wiki/File:Miniature of \%C5\%9Eehzade Mustafa.jpg, http://en.wikipedia.org/wiki/\%C5\%9Eehzade Mustafa). However, he was firstly sent to Amasya from Manisa by Sultan Suleiman with the justification as defending of the east coast of the Ottoman Empire. As a matter of fact, the real intent of Sultan Suleiman was to give more opportunity for the throne to his younger half-brother Şehzade Mehmed, the oldest son of the Russian Hürrem Sultan, whom the French poets call Roxolana. Following the death of his brother Mehmed, Hürrem's other sons Bayezid and Selim were sent to Anatolia as the princes of Konya and Manisa, respectively, for their governor assignments (Fig. 2) (https:// commons.wikimedia.org/wiki/ File:OttomanEmpireIn1683.png) [1].

\section{Murder of Sehzade Mustafa}

Șehzade Mustafa, among the three princes, was the heir to both the throne because of his popularity by the people of Anatolia as well as with the Janissaries. Therefore, Hürrem Sultan was plotting the death of her stepson in order to provide the succession of her son Sehzade Selim. In political league with her son-in-law Grand Vezir Rüstem Pasha, she made Sultan Suleiman believe that Mustafa was a conspirator with 


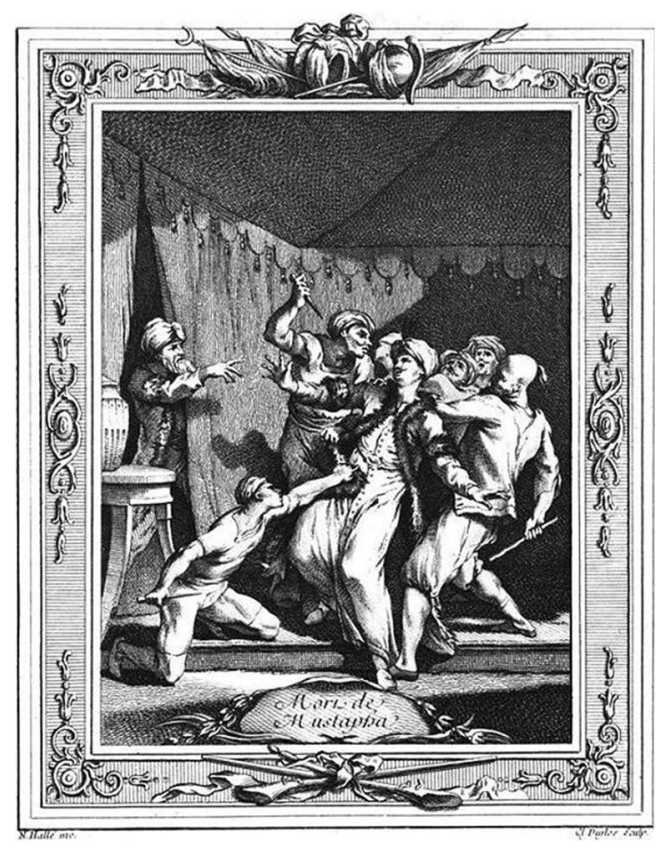

Fig. 3 An engraving depicting the backstabbing of Șehzade Mustafa by a western artist $\mathrm{Cl}$. Duflos, the eighteenth century (from https://commons. wikimedia.org/wiki/File:Mort_de_Mustapha.jpg)

the support of Janissaries to oust his father from the throne (http://en.wikipedia.org/wiki/\%C5\%9Eehzade_Mustafa). In reply to his father's order, he came to his father's tent in the camp at Eregli without any hesitation, he was strangled by

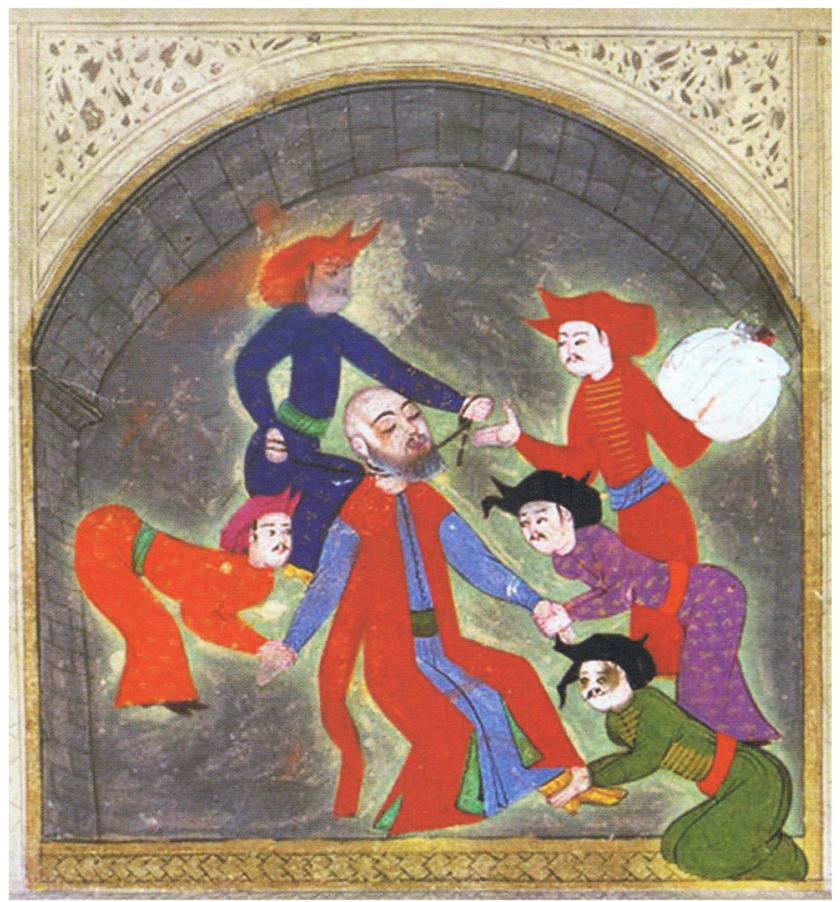

Fig. 4 Strangle of Şehzade Mustafa (from Hünername, II, TSMK, Hazine, nr. 1524, vr. 181a, https://commons.wikimedia.org/wiki/ File:Hunername_181a_Mustafa.jpg)

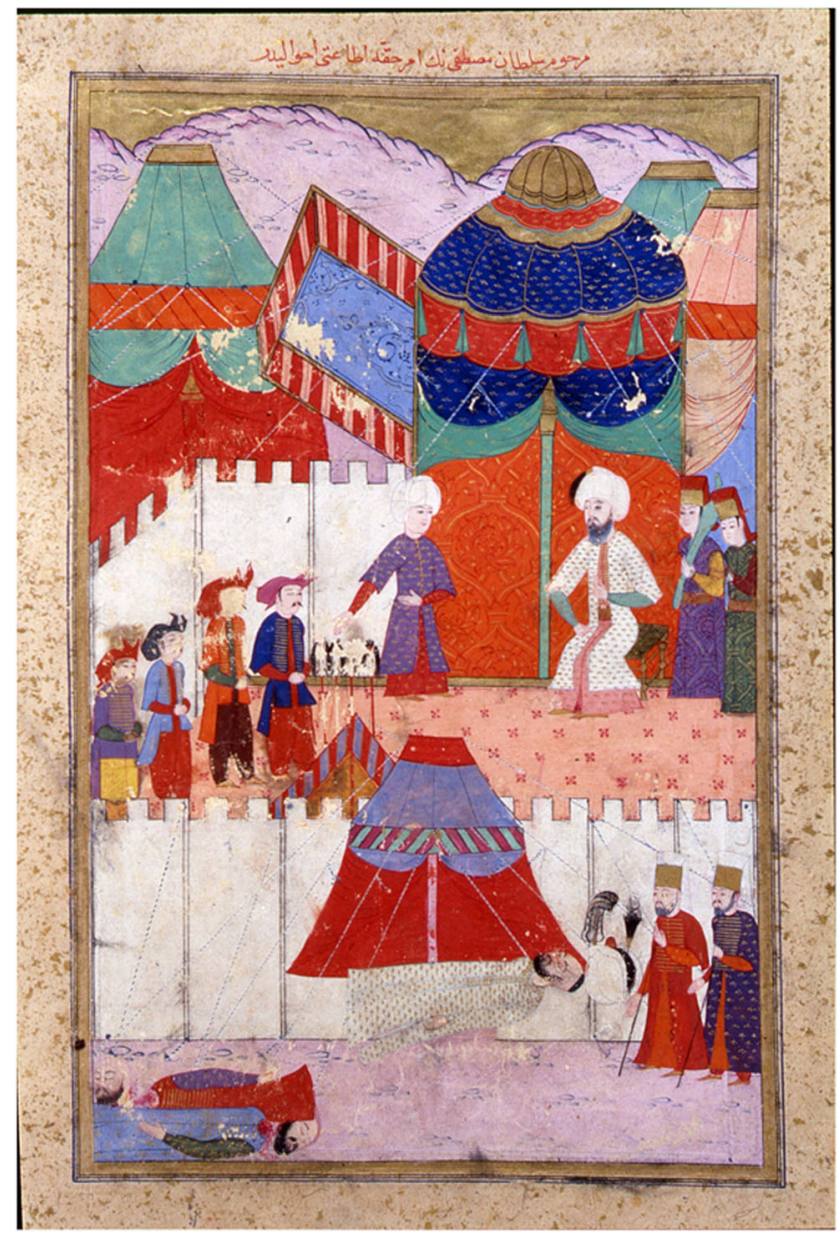

Fig. 5 The cover picture shows a depiction of exhibition of Șehzade Mustafa's corpse after his death in a tent in front of the pavilion in a miniature from the Hünername of Sayyid Lokman. Please also note that the dead bodies of beheaded imrahor and alemdar (standard bearer) are near Șehzade Mustafa's tiptoe. Meanwhile, Sultan Suleiman is sitting on the throne located in front of the pavilion with four of the executioners having finished off their job and are waiting with their face turned to Sultan (Reprinted from Hünername, II, TSMK, Hazine, nr. 1524, vr. $168 \mathrm{~b}$ with permission of the Republic of Turkey Ministry of Culture and Tourism Topkapı Palace Museum Directorate)

Sultan Suleiman's guards in 1553 (Figs. 3, 4 and 5 and Cover Picture) (https://commons.wikimedia.org/wiki/ File:Hunername_181a_Mustafa.jpg, https://commons. wikimedia.org/wiki/File:Hunername_181a_Mustafa.jpg, https://commons.wikimedia.org/wiki/File:Mort_de_ Mustapha.jpg, http://en.wikipedia.org/wiki/\%C5\%9Eehzade_ Mustafa, http://xenohistorian.faithweb.com/neareast/ne13. html).

The treacherous execution of Mustafa excited the Janissaries and Anatolian soldiers of Şehzade Mustafa Janissaries because of Ottoman traditions about succession and his success. Afterwards, the aged Sultan Suleiman, the murderer of his own son, deposed the Grand Vezir to suppress the rebellion. Following this tragedy causing 


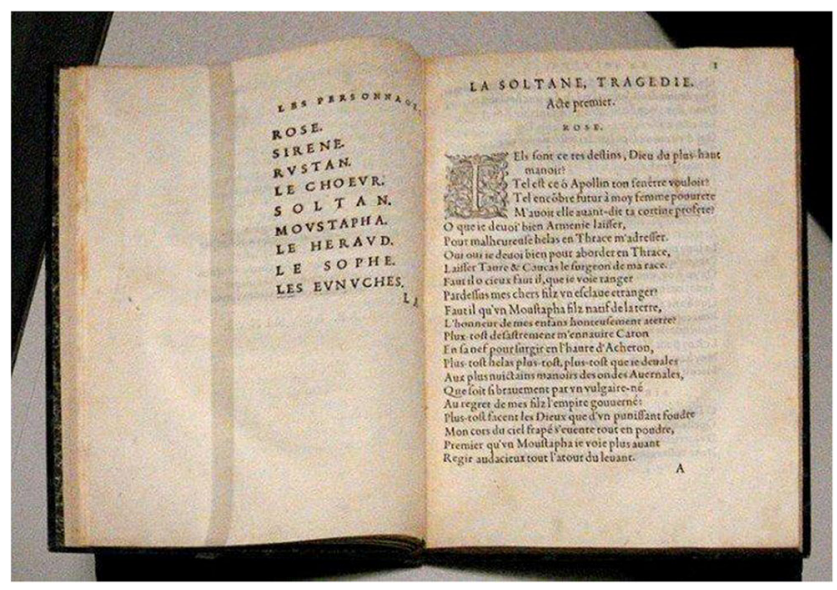

Fig. 6 The murder of Șehzade Mustafa in 1553 was the subject of the 1561 French tragedy La Soltane by Gabriel Bounin (from https://commons. wikimedia.org/wiki/File:La_Soltane_Gabriel_Bounin_1561.jpg)

great pain, Șehzade Selim was the first of degeneration series in the Ottoman Empire.

\section{Profound effects of the execution}

The exemplary role of Hürrem Sultan in the murder of Mustafa was the subject of the French tragedy by La Soltane by Gabriel Bounin (Fig. 6) (https://commons.wikimedia.org/ wiki/File:La_Soltane_Gabriel_Bounin_1561.jpg). The people of Anatolia accepted Mustafa as Sultan Mustafa and his story became a part of both Anatolian Turkish literature, as did in elegy of poet Taşlicalı Yahya for the dead prince (http:// en.wikipedia.org/wiki/\%C5\%9Eehzade_Mustafa, http:// www.tded.org.tr/images/logo/x/taslicali_yahya.pdf).

\section{The role of evil stepmother in the story}

In fact, this tragic story is a cautionary example of negative effects of wicked stepmothers upon the children, although it is an ordinary event for the survival of the state in terms of the history according to some historians. In mythological fairy tales, stepmothers are similar to wild animals that abuse the children. Though differently from cruel historical tragedies, nowadays, "evil" stepmothers have not disappeared, yet as shown by familial events published in chronicle press around the world.

Conflict of interest or ethical standard statement The authors declare no conflict of interest either directly or indirectly related with this article.

\section{Reference}

1. Sakaoğlu N (1999) Sultans of this estate (in Turkish). Oğlak Scientific Publications, İstanbul, p. 137 